\title{
Diverse diazotrophs are present on sinking particles in the North Pacific Subtropical Gyre
}

\author{
Hanna Farnelid ${ }^{1,2} \cdot$ Kendra Turk-Kubo $^{1} \cdot$ Helle Ploug ${ }^{3} \cdot$ Justin E. Ossolinski ${ }^{4}$ James R. Collins $\mathbb{1}^{4,5,6}$. \\ Benjamin A. S. Van Mooy $\mathbb{D}^{4} \cdot$ Jonathan P. Zehr ${ }^{1}$
}

Received: 29 March 2018 / Revised: 3 July 2018 / Accepted: 26 July 2018 / Published online: 16 August 2018

(c) The Author(s) 2018. This article is published with open access

\begin{abstract}
Sinking particles transport carbon and nutrients from the surface ocean into the deep sea and are considered hot spots for bacterial diversity and activity. In the oligotrophic oceans, nitrogen $\left(\mathrm{N}_{2}\right)$-fixing organisms (diazotrophs) are an important source of new $\mathrm{N}$ but the extent to which these organisms are present and exported on sinking particles is not well known. Sinking particles were collected every $6 \mathrm{~h}$ over a 2-day period using net traps deployed at $150 \mathrm{~m}$ in the North Pacific Subtropical Gyre. The bacterial community and composition of diazotrophs associated with individual and bulk sinking particles was assessed using 16S rRNA and nifH gene amplicon sequencing. The bacterial community composition in bulk particles remained remarkably consistent throughout time and space while large variations of individually picked particles were observed. This difference suggests that unique biogeochemical conditions within individual particles may offer distinct ecological niches for specialized bacterial taxa. Compared to surrounding seawater, particle samples were enriched in different size classes of globally significant $\mathrm{N}_{2}$-fixing cyanobacteria including Trichodesmium, symbionts of diatoms, and the unicellular cyanobacteria Crocosphaera and UCYN-A. The particles also contained nifH gene sequences of diverse noncyanobacterial diazotrophs suggesting that particles could be loci for $\mathrm{N}_{2}$ fixation by heterotrophic bacteria. The results demonstrate that diverse diazotrophs were present on particles and that new $\mathrm{N}$ may thereby be directly exported from surface waters on sinking particles.
\end{abstract}

Electronic supplementary material The online version of this article (https://doi.org/10.1038/s41396-018-0259-x) contains supplementary material, which is available to authorized users.

Hanna Farnelid

hanna.farnelid@lnu.se

1 Ocean Sciences Department, University of California at Santa Cruz, Santa Cruz, CA, USA

2 Centre for Ecology and Evolution in Microbial Model Systems, Linnaeus University, Kalmar, Sweden

3 Department of Marine Sciences, University of Gothenburg, Gothenburg, Sweden

4 Department of Marine Chemistry \& Geochemistry, Woods Hole Oceanographic Institution, Woods Hole, MA, USA

5 MIT/WHOI Joint Program in Oceanography, University of Washington, Seattle, WA, USA

6 School of Oceanography and eScience Institute, University of Washington, Seattle, WA, USA

\section{Introduction}

Marine environments exhibit microscale gradients of organic carbon and nutrients, representing diverse microniches for microorganisms to exploit. Particulate organic matter (POM) is ubiquitous in seawater and composed of a mixture of living microorganisms and dead detrital matter, providing 'hotspots' for microbial activity and organic matter remineralization that significantly contribute to biogeochemical element cycling rates [1]. Sinking particles transport organic and inorganic material into the deep ocean, a process known as the ocean's biological pump [2]. Because of their importance, sinking particles and the composition and function of their associated community is receiving increasing interest [3-5]. Compared to larger phytoplankton, the representation of picoplankton in sinking particles has generally been thought to be negligible due to their small size, slow sinking velocity and tight regulation through grazing [6]. However, in recent years the possibility of export of small picoplankton through incorporation into aggregates or fecal pellets has been increasingly recognized 
$[7,8]$ and has been proposed to be in proportion to their total net primary production $[9,10]$.

The bacterial community composition of particulate material has been assessed in several different environments, suggesting that particle attached communities are phylogenetically distinct from that of the surrounding water (e.g., [5, 11-13]). Groups that are enriched on sinking particles include members of Bacteroidetes, Planctomycetes, and Roseobacter [3, 14]. Since particles are thought to represent diverse microscale conditions, bulk analyses of sedimented or size fractionated material may not provide high-resolution insights into the associated communities of individual particles. In addition, only few studies have considered degradation dynamics during sample collection [15]. Thus, molecular characterization of individual particles collected during short time scales may provide novel insights into the composition of sinking particles.

The North Pacific Subtropical Gyre (NPSG) is characterized by low concentrations of macronutrients and warm surface water temperatures. The ecosystem is dominated by relatively low rates of primary production and low particulate organic carbon (POC) flux at the base of the euphotic zone [16]. Primary production in the NPSG is limited by nitrogen $(\mathrm{N})$ and the dissolved dinitrogen gas $\left(\mathrm{N}_{2}\right)$ is only available to $\mathrm{N}_{2}$-fixing organisms (diazotrophs), which can reduce $\mathrm{N}_{2}$ into bioavailable ammonium. In the NPSG, diazotrophs contribute to a significant portion (26-47\% during the years 2006-2013) of particulate nitrogen export [17]. However, the fate of the newly fixed $\mathrm{N}_{2}$ in the marine food web is not fully understood and the extent to which cells of dead or living $\mathrm{N}_{2}$-fixing organisms are exported from the euphotic zone on sinking particles may vary among the diverse species $[18,19]$. In the oligotrophic open ocean, significant diazotrophs associated with larger size fractions of plankton include the widely distributed filamentous $\mathrm{N}_{2}$-fixing cyanobacterium Trichodesmium [20] and heterocystous-cyanobacterial endosymbionts of diatoms [21]. While diatoms can be exported directly due to their relatively heavy silicified cell walls [22] Trichodesmium has been suggested to have low direct export efficiency [23]. Small unicellular cyanobacterial diazotrophs (UCYN), are also highly prevalent (e.g., [24]) and may consequently play a significant role in POC export, but little is known about their possible export mechanisms.

$\mathrm{N}_{2}$ fixation is an energy demanding and oxygen $\left(\mathrm{O}_{2}\right)$ sensitive process. Cyanobacterial diazotrophs have various mechanisms for protecting the nitrogenase enzyme from inactivation by $\mathrm{O}_{2}$ including temporal separation of $\mathrm{N}_{2}$ fixation and photosynthesis, heterocyst formation, and symbiotic interactions. The unicellular cyanobacterial diazotrophs (UCYN-A, UCYN-B and UCYN-C) exhibit a range of cellular strategies and interactions [25]. UCYN-A lives in association with a photosynthetic picoeukaryote, while UCYN-B (Crocosphaera sp.) can be found freeliving but may also form colonies, aggregates or live in symbiosis with a diatom [26]. The physiology of the broadly defined UCYN-C group is still largely unknown. To explore diazotroph diversity, the nifH gene, a gene encoding a subunit of the nitrogenase enzyme, has been frequently used. In recent years nifH gene sequences related to non-cyanobacterial, heterotrophic diazotrophs have been reported from various oligotrophic ocean regions [27, 28]. How heterotrophic diazotrophs support $\mathrm{N}_{2}$ fixation in the oxygenated surface ocean is not yet understood and the significance to global $\mathrm{N}_{2}$ fixation rates is debated $[29,30]$. It has been proposed that heterotrophic $\mathrm{N}_{2}$ fixation may take place in close association with phytoplankton or within interiors of particles but this has not yet been resolved [29].

Sinking particles constitute a diverse spectrum of environments for their colonizers based on the history of the organic matter by which they are formed. Low $\mathrm{O}_{2}$ concentrations within sinking particles and aggregates due to microbial remineralization of organic matter have previously been reported [31, 32]; these microenvironments would be potential niches for $\mathrm{O}_{2}$-sensitive diazotrophs. In this study, we investigate the bacterial composition and the associated populations of diazotrophs on both individually picked and bulk samples of sinking particles in the NPSG, and compare the community composition with that of the surrounding seawater. Using high-throughput nifH gene amplicon sequencing we also investigate whether diazotroph biomass is exported on sinking particles and if particles could be potential loci for heterotrophic $\mathrm{N}_{2}$ fixation in the oligotrophic ocean.

\section{Methods}

\section{Sample collection at sea}

Lagrangian sampling was performed during the HOELegacy 2B cruise (KOK1507) in the NPSG onboard the R/ $\mathrm{V}$ Ka'imikai-O-Kanaloa in an anticyclonic eddy (Fig. 1). Water column properties $(0-200 \mathrm{~m})$ were determined from vertical depth profiles using a rosette of Niskin bottles equipped with a fluorometer and temperature, conductivity and oxygen sensors every $4 \mathrm{~h}$ during 25 July to 3 August 2015. Surface-tethered particle net traps with a diameter of $1.25 \mathrm{~m}\left(1.23 \mathrm{~m}^{2}\right.$ area of collection) and a $20 \mu \mathrm{m}$ mesh cod end [33] were deployed at $150 \mathrm{~m}$ for $\sim 5-6 \mathrm{~h}$. A total of 7 deployments (Fig. 1, D1-D7) were conducted over a $48 \mathrm{~h}$ period (Table S1). An acoustic release was used to close the traps prior to recovery so that material from the overlying water column was not inadvertently sampled. Traps were recovered immediately upon closure, except in the case of net trap D4, which was closed after $\sim 6 \mathrm{~h}$ but could not be 
Fig. 1 Map showing the sampling location of the net traps (D1-D7) which were collected within a total distance of $16 \mathrm{~km}, 150 \mathrm{~m}$ seawater samples (S1 and S2) and vertical depth profile collected for nifH community analysis located in an anticyclonic eddy north of Hawaii adapted from Wilson et al. [50]. a Patterns of sea level anomaly. b Sampling locations

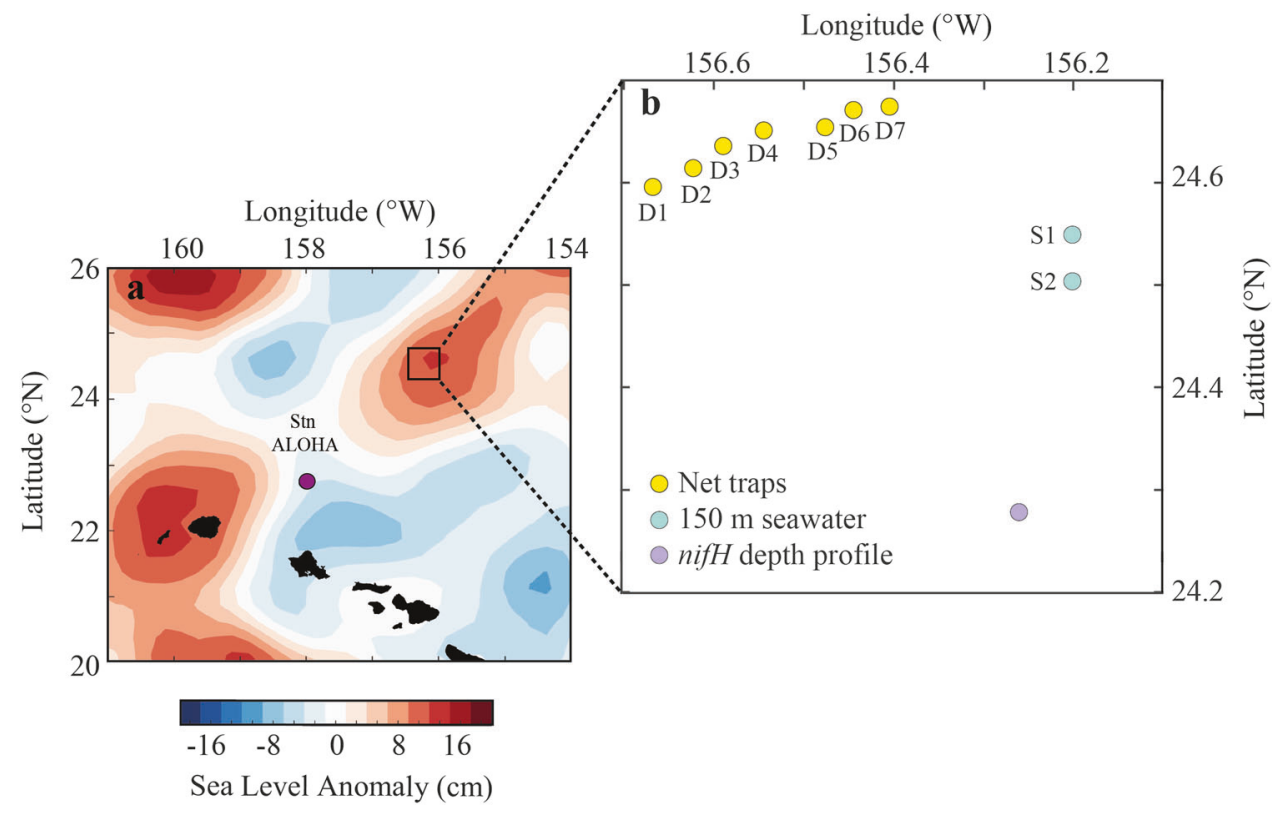

recovered until $\sim 13 \mathrm{~h}$ after it was deployed (Table S1). Particle material was divided in acid-rinsed $500 \mathrm{ml}$ HDPE bottles as described in Collins et al. [34] and processed immediately. Bulk particle samples were obtained by filtering $10 \mathrm{ml}$ of the material collected in the traps through a $0.2 \mu \mathrm{m}$ pore size Supor filter (Pall Corporation, New York, NY, USA). The filters were placed in cryo tubes and immediately frozen in liquid $\mathrm{N}$.

\section{Sampling of individual particles and imaging}

Individual particles (220 in total; $\sim 20-500 \mu \mathrm{m}$ in diameter) were visualized using a Nikon AZ100 microscope and a Nikon NI-150 illuminator and images were acquired using a Nikon DS-Fi1 camera. Individual particles were handpicked using a micropipette and placed in PCR tubes. The pipette was rinsed with $2 \mu \mathrm{l}$ sterile filtered $150 \mathrm{~m}$ seawater and the rinse was placed together with the particle in the tube. The tubes were frozen at $-80{ }^{\circ} \mathrm{C}$. In parallel, individual particles were placed on glass slides, fixed in $2 \%$ paraformaldehyde and mounted using ProLong Diamond with DAPI (Molecular probes, Eugene, OR, USA). Images of DAPI stained particles and chlorophyll a containing cells were obtained using a Zeiss Axioplan 2 and a Zeiss AxioCam HRc camera and the software Zeiss AxioVision Rel.4.8. The filter cube for the chlorophyll a detection was a Zeiss high efficiency filter set 09, with excitation BP at 450-490 $\mathrm{nm}$ and emission at LP515 nm.

To allow for a comparison between the particle samples and the surrounding seawater, seawater samples were collected from $150 \mathrm{~m}$ (Fig. 1, S1 and S2). Seawater (2 1) was filtered gently through a $10 \mu \mathrm{M}$ polycarbonate filter (Sterlitech, Kent, WA, USA) or a $3 \mu \mathrm{M}$ polycarbonate filter
(Sterlitech, Kent, WA, USA) and subsequently though a $0.2 \mu \mathrm{M}$ Supor filter in $25 \mathrm{~mm}$ Swinnex filter holders (Millipore, Billerca, MA, USA) using a peristaltic pump. Samples (2 1) were also collected from a vertical seawater profile $(5,15,25,35,45,60,75$, and $100 \mathrm{~m}$; Fig. 1) on $0.2 \mu \mathrm{M}$ Supor filters to allow for analysis of diazotroph community composition. The filters were placed in sterile $1.5 \mathrm{ml}$ cryovials containing $0.1 \mathrm{~g}$ autoclaved glass beads (BioSpec, Bartlesville, OK, USA), immediately flash frozen in liquid $\mathrm{N}$ and stored at $-80^{\circ} \mathrm{C}$ until DNA extraction.

\section{DNA extraction and particle lysis}

DNA was extracted from seawater and bulk particle samples using the Qiagen Plant Minikit and QIAcube (Qiagen, Valencia, CA, USA). The filters were thawed at room temperature and $400 \mu \mathrm{l}$ AP1 buffer was added to the sample tubes. The samples were freeze-thawed three times using liquid $\mathrm{N}$ and a $65^{\circ} \mathrm{C}$ water bath and shaken at full speed for 2 min in a FastPrep-24 bead beater (MP Biomedicals, Irvine, CA, USA). The samples were Proteinase $\mathrm{K}$ treated ( $45 \mu \mathrm{l}$ of $20 \mathrm{mg} \mathrm{ml}^{-1}$ Proteinase $\mathrm{K}$ ) for $1 \mathrm{~h}$ at $55^{\circ} \mathrm{C}$ with moderate shaking and RNase A treated for $10 \mathrm{~min}$ at $65^{\circ} \mathrm{C}$. The filters were removed from the sample tubes using sterile needles and the further extraction steps were carried out according to the manufacturer's protocol. Samples of individual particles were prepared for PCR amplification by subjecting them to three freeze-thaw cycles using liquid $\mathrm{N}$ and a $65^{\circ} \mathrm{C}$ water bath, adding Lyse and Go PCR Reagent (10 $\mu$; Thermo Scientific, Rockford, IL, USA) and placing the tubes in a thermocycler with a program of $30 \mathrm{~s}$ at $65^{\circ} \mathrm{C}$, $30 \mathrm{~s}$ at $8{ }^{\circ} \mathrm{C}, 90 \mathrm{~s}$ at $65^{\circ} \mathrm{C}, 180 \mathrm{~s}$ at $97^{\circ} \mathrm{C}, 60 \mathrm{~s}$ at $8^{\circ} \mathrm{C}, 180 \mathrm{~s}$ 
at $65^{\circ} \mathrm{C}, 60 \mathrm{~s}$ at $97^{\circ} \mathrm{C}, 60 \mathrm{~s}$ at $65^{\circ} \mathrm{C}$ and an $80^{\circ} \mathrm{C}$ hold while the PCR amplification mixtures were set up.

\section{$16 S$ rRNA and nifH gene amplicon sequencing and sequence analysis}

A targeted amplicon sequencing (TAS) approach as described by Green et al. [35] was used to amplify the V3V4 variable region of the 16S rRNA gene with the CS1_341F (5'-ACACTGACGACATGGTTCTACACCTA CGGGNGGCWGCAG-3') and CS2_806R (5'-TACGGTAGCAGAGACTTGGTCTGACTACHVGGGTATCTA-

ATCC-3') primers. The PCR was performed in $25 \mu \mathrm{l}$ reaction volumes with $1 \times$ PCR buffer, $2.5 \mathrm{mM} \mathrm{MgCl}_{2}, 200$ $\mu \mathrm{M}$ dNTPs, $0.25 \mu \mathrm{M}$ of each primer and $0.3 \mu$ Invitrogen Platinum Taq (Invitrogen, Carlsbad, CA, USA). The PCR conditions were 5 min denaturation at $95^{\circ} \mathrm{C}$, followed by 25 cycles of $40 \mathrm{~s}$ denaturation at $95^{\circ} \mathrm{C}$, annealing for $40 \mathrm{~s}$ at $53{ }^{\circ} \mathrm{C}$ and elongation for $60 \mathrm{~s}$ at $72^{\circ} \mathrm{C}$, and ending with a final elongation for $7 \mathrm{~min}$ at $72{ }^{\circ} \mathrm{C}$. For amplification of the nifH gene, a nested PCR protocol was performed using the nifH3 and nifH4 primers in the first PCR followed by a second amplification with nifH1 and nifH2 primers [36] with CS1 and CS2 linkers [37]. For the PCR reaction mixtures $1 \times$ PCR buffer, $4 \mathrm{mM} \mathrm{MgCl} 2,200 \mu \mathrm{M}$ dNTPs, 0.5 $\mu \mathrm{M}$ of each primer and $0.3 \mu \mathrm{l}$ Invitrogen Platinum Taq (Invitrogen) were used. The PCR conditions were $3 \mathrm{~min}$ denaturation at $95^{\circ} \mathrm{C}$, followed by 25 cycles in the first amplification and 30 cycles in the second PCR of $30 \mathrm{~s}$ denaturation at $95^{\circ} \mathrm{C}$, annealing for $30 \mathrm{~s}$ at $55^{\circ} \mathrm{C}$ for the first amplification and $57^{\circ} \mathrm{C}$ for the second PCR and elongation for $45 \mathrm{~s}$ at $72{ }^{\circ} \mathrm{C}$, and ending with a final elongation for 7 min at $72{ }^{\circ} \mathrm{C}$.

For the seawater and bulk particle samples, $1 \mu \mathrm{l}$ of the DNA extract was used as a template and PCR reactions were run in triplicates. For the individual particles, $2.5 \mu \mathrm{l}$ of the lysed solution was used as a template. Negative extraction controls (blank filter) and negative PCR controls (only water instead of template) were included and did not result in any visible amplification when $5 \mu \mathrm{l}$ amplification product was loaded onto a $1.4 \%$ agarose gel. The amplicons were submitted for sequencing to the DNA Services (DNAS) Facility at the University of Illinois at Chicago. At the DNAS Facility an additional PCR amplification was performed to incorporate barcodes and sequencing adaptors to the final amplicons. The sequencing was performed on an Illumina MiSeq sequencer using standard V3 chemistry with paired-end, $300 \mathrm{bp}$ long reads and demultiplexing of reads was performed on instrument.

For the 16S rRNA gene libraries, the forward and reverse FASTQ files were merged using PEAR [38]. To obtain high-quality data, the sequences were trimmed using a quality threshold of $p=0.01$ in the software package CLC genomics workbench (v7; CLC Bio, Qiagen, Boston, MA, USA) and sequences that were less than $350 \mathrm{bp}$ in length and lacked either primer were discarded. Chimeric sequences were identified using the USEARCH [39] algorithm as compared with the GreenGenes 13.8 database [40] and filtered from the dataset. De novo operational taxonomic unit (OTU) clusters (97\% sequence similarity) were generated, taxonomy of the OTU centroid sequence was assigned using UCLUST in the QIIME v1.8 pipeline [41] and singletons were removed. Representative sequences for each OTU were generated and closest relatives were identified using Blastn. The libraries were rarefied to 15 000 sequence depth and samples with $<15,000$ sequences were removed. The number of observed OTUs, Shannon H and Chao1 diversity indices were calculated using Explicet [42]. A Bray-Curtis similarity matrix was calculated using the software package Primer6 (Primer-E). To identify OTUs whose abundance in seawater differed significantly from that in bulk particle samples based on hierarchal taxonomy, a two-sided Welch's $t$-test with confidence intervals was used in the STAMP v2.01 software [43]. Statistical confidence intervals were calculated for a $95 \%$ nominal coverage. PERMANOVA analyses were done using the vegan package in $\mathrm{R}$, and function adonis using 999 permutations.

The paired-end FASTQ files from the nifH amplicon sequencing were merged using the software package PEAR [38]. The libraries were quality filtered (phred20) using the QIIME pipeline [41]. A de novo chimera check and OTU clustering (97\% similarity) was done using USEARCH61 [39], representative sequences were generated and singletons were removed from the dataset. The sequences were translated and aligned using MEGA6.06 [44]. OTUs with representative sequences containing stop codons or frameshifts were removed from the dataset, corresponding to $<9 \%$ of the total number of sequence reads. To identify UCYN-A sublineages, all UCYN-A reads were extracted from the dataset by clustering all reads (post-chimera check) at $95 \%$ nucleotide (nt) identity after adding representative UCYNA sequences. Oligotypes were determined using the oligotyping pipeline created by Eren et al. [45] using the same entropy positions determined in Turk-Kubo et al. [46]. Representative nifH sequences were annotated based on nifH cluster classification [47] according to the recently described CART model [48] complemented by a phylogenetic tree analysis to identify groups of cyanobacterial diazotrophs. The sequences have been submitted to NCBI Sequence Read Archive (SRA) with accession number SRP111426.

\section{Abundance of diazotrophs}

To enumerate diazotroph groups in the vertical profile, quantitative polymerase chain reaction (qPCR) targeting 
UCYN-A1, UCYN-B, Trichodesmium spp., and three diatom-diazotroph associations (Het-1, Het-2, and Het-3) was used and conducted as previously described [49].

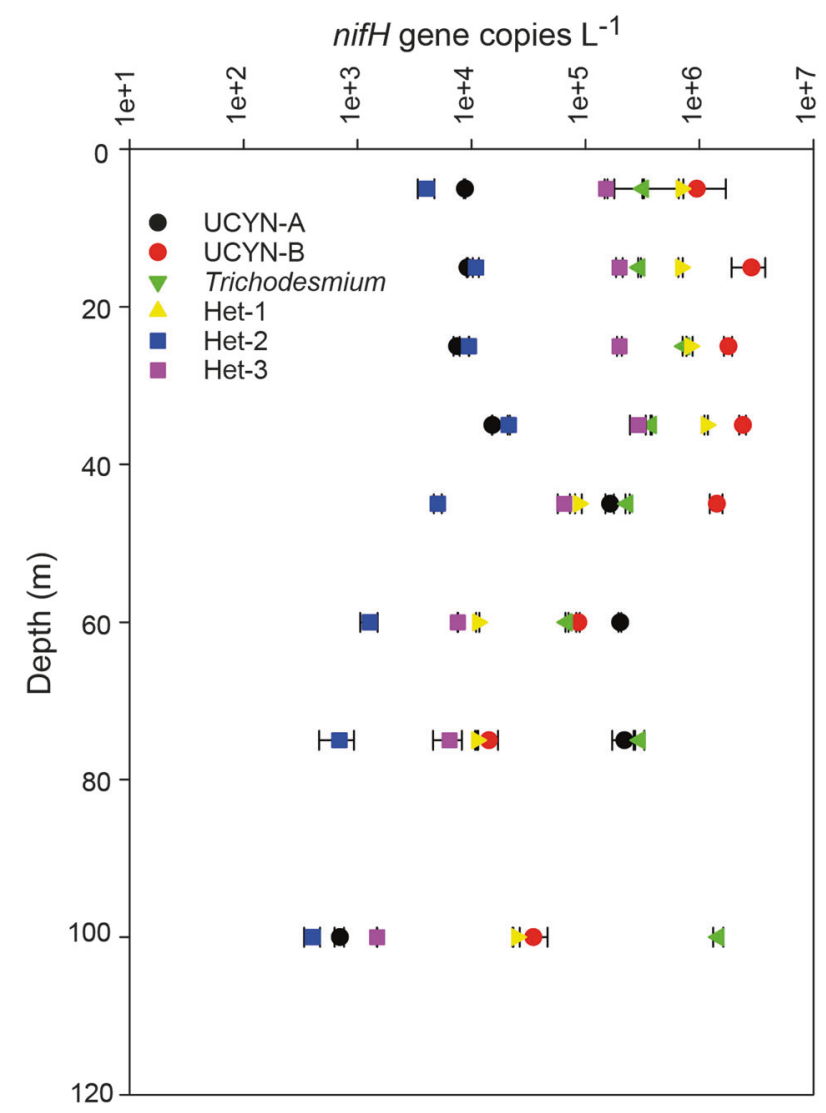

Fig. 2 Average nifH gene abundances for target groups measured using qPCR in a vertical profile. Error bars indicate standard deviations based on triplicate measurements

Fig. 3 Microscopy images showing examples of individual particles from particle samples collected from net traps at 150 $\mathrm{m}$. a-d The particulate material ranged from partly decayed planktonic organisms to loosely associated aggregates and fecal pellets. e, f DAPI stained particles showing that the particles were associated with both chlorophyll a containing cells (red) and non-pigmented cells (blue)

\section{Results}

\section{Water column features in the sampling area}

The area of sampling was characterized by an anticyclonic eddy feature coinciding with elevated chlorophyll a and productivity (described in ref. [50]; Fig. 1). The mixed layer depth averaged around $30 \mathrm{~m}$ and the deep chlorophyll a maximum varied between 120 and $130 \mathrm{~m}$. The surface photoautotroph population was dominated by Prochlorococcus at $1.6 \times 10^{8}$ cells $1^{-1}$. Synechococcus and photosynthetic picoeukaryotes averaged $1.1 \times 10^{6}$ and $0.4 \times$ $10^{6}$ cells $1^{-1}$, respectively [50]. The abundances of key diazotroph groups were determined, indicating that Crocosphaera sp. (UCYN-B) was present in unusually high abundances in the upper $50 \mathrm{~m}$ (average $1.9 \times 10^{6}$ nifH gene copies $1^{-1}$; Fig. 2). UCYN-A1, Trichodesmium spp., and three diatom-diazotroph associations (Het-1, Het-2, and Het-3) were also detected throughout the vertical profile $(5-100 \mathrm{~m})$ albeit at lower abundances (Fig. 2).

\section{Microscopic analysis of particles}

Sinking particles were visualized and picked individually under a dissection light microscope. Many of the particles appeared to be loosely associated material, but fecal pellets and aggregates with a more dense appearance were also observed (Fig. 3). Filaments of Trichodesmium were observed in material from the net traps D1, D4, D5, and D6. Epifluorescence microscopy showed that the particles were heavily colonized by photosynthetic (chlorophyll a containing) and non-photosynthetic bacteria of various sizes (Fig. 3).
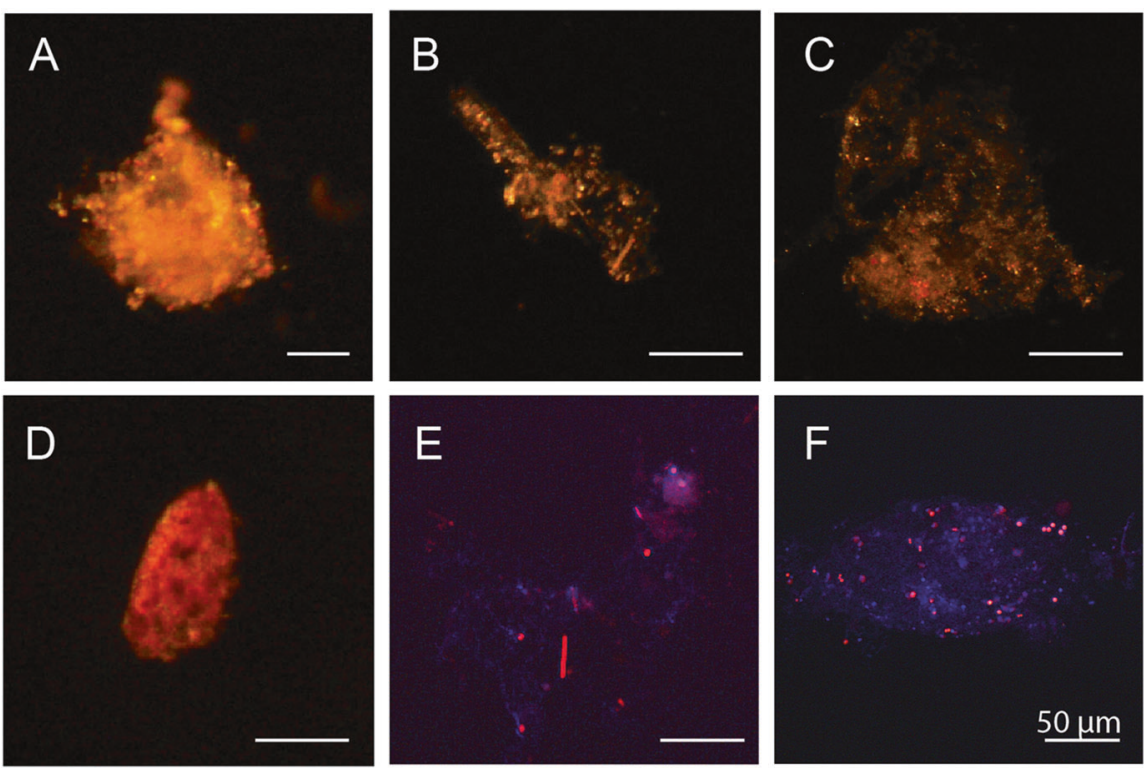


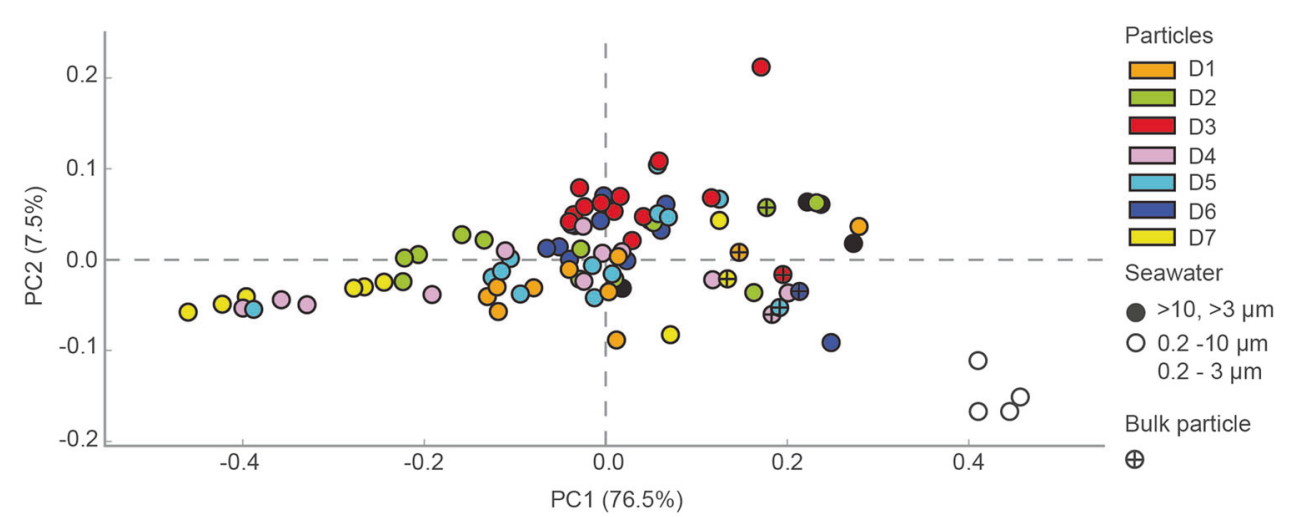

Fig. 4 Principal component analysis (PCA) plot calculated using the 16S rRNA gene class level of the taxonomical hierarchy for each sample. The two first principal components are plotted with the proportion of variance explained by each component indicated in brackets. The numbers of sequences were normalized to the total number of

\section{S rRNA gene composition on particles}

The bacterial composition of the bulk particle samples, individual particles and seawater samples from the depth of deployment $(150 \mathrm{~m})$ was investigated. In total, $>2$ million high quality 16S rRNA gene sequences were analyzed (Supplementary Table S2). The lowest diversity was seen for the individual particles where the number of OTUs varied between 387 and 875 OTUs. The highest diversity of the bacterial community was observed in the seawater samples (up to 1706 OTUs; Supplementary Figure S1). Principal coordinate analysis showed that the bacterial community composition of the particles on both the class and OTU level was most similar to the $>10$ and $>3 \mu \mathrm{m}$ seawater samples; Fig. 4 and Supplementary Figure S2). The bulk particle samples exhibited less variation in composition compared to the individual particles and were significantly different from the $0.2-10$ and $0.2-3 \mu \mathrm{m}$ seawater samples (PERMANOVA, $p=0.005$; Fig. 4 and Supplementary Figures S2 and S3). The individual particles were highly variable in composition but a few particles collected from the same net trap had relatively high similarity ( $>75 \%$ Bray-Curtis similarity; Supplementary Figure S3).

To identify groups whose abundance differed significantly between the small size fraction of the seawater samples $(0.2-10$ and $0.2-3 \mu \mathrm{m})$ and the bulk particle samples, a group comparison between the mean proportions of sequences per sample was done both at class and OTU level. The particle sequence libraries were dominated by Gammaproteobacteria (Fig. 5), including Alteromonadales, Vibrionales and Oceanospirillales. Bacteroidetes was the second most abundant phylum, and Flavobacteria were significantly $(p<0.001$; Welch's $t$-test $)$ enriched in the particle samples compared to the small size fraction sequences in each library and unclassified sequences were retained. Each sample is represented by a circle, with a color indicating the net trap number or the fraction of the seawater. Bulk particle samples for each net trap are labelled with a $(+)$ in the circle

seawater samples (Fig. 5). At the fine-scale OTU level, 24 OTUs with $>1 \%$ difference in mean proportion were identified (Table 1). Typically free-living genera such as Synechoccoccus, Prochlorococcus and Pelagibacter were significantly ( $p<0.01$; Welch's $t$-test) enriched in the seawater samples compared to the bulk particle samples while OTUs within the order Alteromonadales (Alteromonas; OTU_4074 and Pseudoalteromonas; OTU_26436) were significantly $(p<0.01$; Welch's $t$-test) enriched on particles (Table 1).

The relative abundance of chloroplast sequences was significantly higher in the bulk particle samples compared to the seawater samples $(p<0.001$; Welch's $t$-test $)$ and the most frequently detected chloroplast sequences were Stramenopiles $(2.0 \pm 2.2 \%$ mean sequence proportion) and Haptophycea $(0.5 \pm 0.3 \%$ mean sequence proportion; data not shown). Notably, the chloroplast sequences of Rhizosolenia imbricate (OTU_16894), a diatom which has been reported to contain the endosymbiotic $\mathrm{N}_{2}$-fixing bacterium Richelia intracellularis [51], were among the most highly enriched OTUs in the bulk particle samples (Fig. 6 and Table 1). In addition, OTUs closely related ( $>97 \%$ identity) to the 16S rRNA gene sequences of the diazotrophs Crocosphaera, Trichodesmium and UCYN-A were consistently present and significantly enriched in the bulk particle samples compared to the seawater samples (Fig. 6).

\section{Presence and composition of diazotrophs on particles}

To identify the diazotrophs present on particles the nifH gene was amplified from bulk particle and individual particle samples. All of the bulk particle samples had strong nifH gene amplicons, visualized through gel electrophoresis. For the individual particles, nifH genes amplified from 
Fig. 5 Bar plot showing the mean proportion and the difference in mean proportion (16S rRNA gene) between the respective groups of significantly enriched $(p<0.05$; Welch's $t$-test) classes with a difference in mean proportions of $>1 \%$. Error bars indicate standard deviation and corrected $p$-values are indicated to the right. The small size fraction seawater samples $(0.2-10$ and $0.2-3 \mu \mathrm{m})$ are shown in purple, and bulk particle samples from each net trap (D1-D7) are shown in green
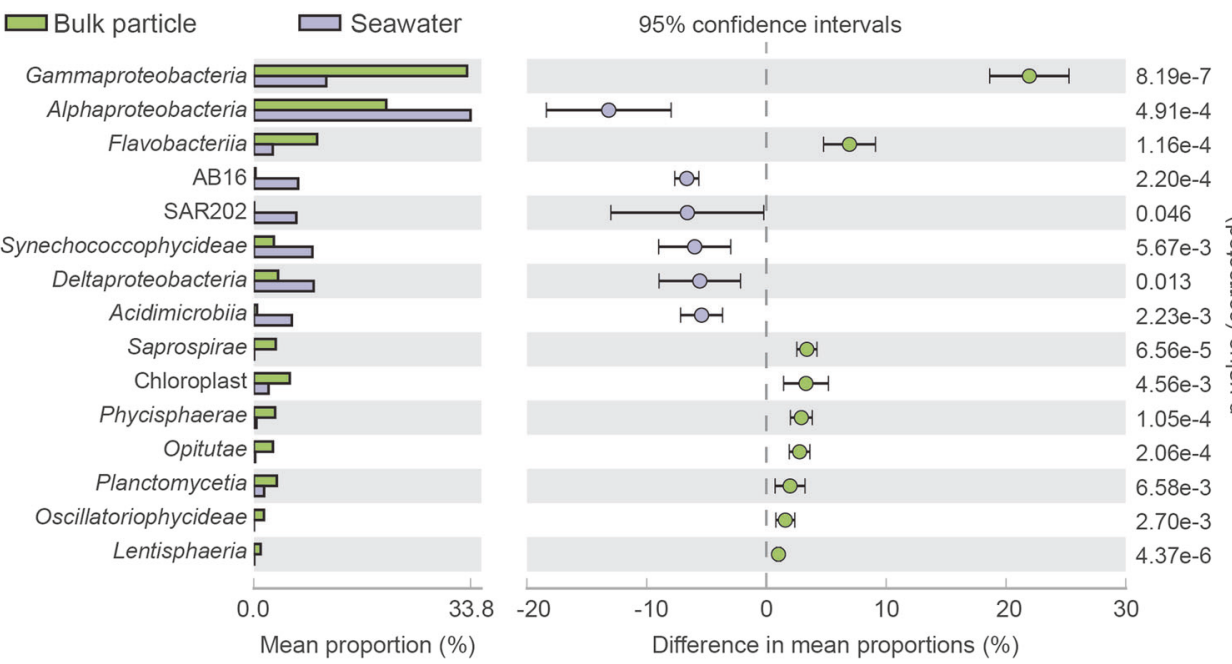

49 out of the 76 individual particles (Supplementary Tables S1 and S2). For the particles sampled from net traps D3 and D6, all resulted in nifH amplicons while for particles from net traps D1 and D2 only $<30 \%$ of the investigated particles amplified.

In total, $>4.1$ million high quality nifH sequences in 511 OTUs (97\% amino acid similarity clustering) were analyzed (Supplementary Table S2). Classification of the nifH OTUs using a tree-placement approach showed that $44.5 \%$ of sequences in bulk particle samples were nifH Cluster 1B Cyanobacteria (defined in [47]) with representative OTUs from endosymbionts of diatoms (Het-1, Het-2 and Het-3), Trichodesmium, UCYN-A, Crocosphaera (UCYN-B) and Cyanothece (UCYN-C) (Supplementary Table S3). The proportion of nifH Cluster 1B was lower in the bulk particle samples compared to the vertical profile where Trichodesmium, UCYN-A and UCYN-B were the most prominent $1 \mathrm{~B}$ phylotypes. The UCYN-A sequences in the bulk particle samples consisted primarily of the UCYN-A sublineages UCYN-A1 and UCYN-A3. The proportion of UCYN-A3 sequences was consistently higher compared to UCYN-A1 which has previously been reported as the dominant lineage in the NPSG water column ([46]; Supplementary Figure S4). The nifH Cluster IG, a nifH cluster comprised primarily of gammaproteobacterial phylotypes was represented by $50.3 \%$ of the bulk particle sequences (Supplementary Table S3). Sequences affiliating with nifH Cluster III, composed of diverse sequences mostly from anaerobic bacteria and archaea, Cluster 1P, which includes Gammaand Betaproteobacteria phylotypes, and Cluster $1 \mathrm{~J} / 1 \mathrm{~K}$, which includes Alpha- and Betaproteobacteria were consistently recovered at a higher relative abundances in the bulk particle samples compared to the vertical profile (Supplementary Table S3).

The nifH composition of the bulk particle samples was highly consistent during the $48 \mathrm{~h}$ sampling, (76.6-90.5\%
Bray-Curtis similarity) while large variations between individual particles were observed (Fig. 7 and Supplementary Figure S5). The composition of individual particles was highly dependent on the net trap sample from which the particles were collected. For example, Crocosphaera (UCYN-B; Cluster 1B) was most prevalent in individual particles collected from the D3 and D5 traps (Fig. 7). Similarly, OTU_1527 (Cluster III) which had 96\% nt identity to a sequence reported from Seto Inland Sea in Japan (Accession number LC063947; [52]) and 99\% amino acid identity to Desulfovibrio putealis (Accession number WP_027192250) was the dominating OTU in particles collected from net trap D6 (up to $87 \%$ ). The OTU_1 (Cluster 1 P), affiliating with the Betaproteobacteria Azoarcus sp. and Dechloromonas aromatica $(<88 \% \mathrm{nt}$ identity), was most frequently detected in individual particles collected from net trap D3 (Fig. 7). Three gammaproteobacterial OTUs were represented among the eight most abundant OTUs including OTU_1107, representing the widespread gammaproteobacterial group $\gamma 24774$ A11 $(98 \%$ nt identity; [28, 53]). However, although the gammaproteobacterial OTUs represented a large proportion of sequences in the bulk particle samples, their presence in individual particles was highly variable (Fig. 7 and Supplementary Table S3).

\section{Discussion}

Large diameter net traps allow for collection of sinking particles over comparatively short timescales (4-7 h). Over the time course spanning $48 \mathrm{~h}$, when our seven net traps were deployed and collected, the community composition of the bulk particle samples were relatively similar to one another (Fig. 4 and Supplementary Figure S2). This suggests that there is a temporal consistency 
Table 1 Affiliation and closest relatives in Genbank to the enriched $(>1 \%$ difference in mean proportions) $16 \mathrm{~S}$ rRNA gene OTUs in bulk particle samples (D1-D7) compared to seawater samples $(0.2-10$ and $0.2-3 \mu \mathrm{m})$

\begin{tabular}{|c|c|c|c|c|}
\hline OTU ID & Class affiliation & Closest relative & Similarity & $\begin{array}{l}\text { Accession } \\
\text { number }\end{array}$ \\
\hline \multicolumn{5}{|c|}{ Enriched in bulk particle samples } \\
\hline OTU_43683 & Alphaproteobacteria & Shimia sp. & $100 \%$ & KT720466.1 \\
\hline OTU_20532 & Alphaproteobacteria & Tropicibacter multivorans & $100 \%$ & KP843700.1 \\
\hline OTU_16894 & Chloroplast & Rhizosolenia & $97 \%$ & KJ958482.1 \\
\hline OTU_25878 & Flavobacteriia & $\begin{array}{l}\text { Unclassified Bacteroidetes; } \\
\text { Flavobacteriales }\end{array}$ & & \\
\hline OTU_4074 & Gammaproteobacteria & Alteromonas sp. & $100 \%$ & KX356439.1 \\
\hline OTU_26436 & Gammaproteobacteria & Pseudoalteromonas sp. & $100 \%$ & KX806641.1 \\
\hline OTU_22018 & Gammaproteobacteria & $\begin{array}{l}\text { Unclassified } \\
\text { Gammaproteobacteria; } \\
\text { Oceanospirillales }\end{array}$ & & \\
\hline OTU_29878 & Gammaproteobacteria & Thalassolituus oleivorans & $97 \%$ & KF170318.1 \\
\hline OTU_18280 & Gammaproteobacteria & Photobacterium angustum & $100 \%$ & KC534344.1 \\
\hline OTU_44280 & Opitutae & $\begin{array}{l}\text { Uncultured Verrucomicrobia; } \\
\text { Puniceicoccaceae }\end{array}$ & $99 \%$ & HQ675288.1 \\
\hline OTU_8705 & Saprospirae & $\begin{array}{l}\text { Unclassified Bacteroidetes; } \\
\text { Saprospiraceae }\end{array}$ & & \\
\hline \multicolumn{5}{|c|}{ Enriched in free-living seawater samples } \\
\hline OTU_19700 & Acidimicrobiia & Uncultured Actinobacteria & $100 \%$ & HQ675198.1 \\
\hline OTU_36708 & Alphaproteobacteria & Pelagibacteraceae & $100 \%$ & HQ675347.1 \\
\hline OTU_39648 & Alphaproteobacteria & Pelagibacter sp. & $100 \%$ & LN850157 \\
\hline OTU_30217 & Alphaproteobacteria & Pelagibacteraceae & $99 \%$ & JF488446.1 \\
\hline OTU_817 & Alphaproteobacteria & Uncultured Alphaproteobacteria & $97 \%$ & JF488548.1 \\
\hline OTU_18321 & Alphaproteobacteria & Pelagibacteraceae & $99 \%$ & HQ675689.1 \\
\hline OTU_26273 & Deltaproteobacteria & $\begin{array}{l}\text { Uncultured Deltaproteobacteria; } \\
\text { Sva0853 }\end{array}$ & $99 \%$ & U65908.1 \\
\hline OTU_6835 & Deltaproteobacteria & $\begin{array}{l}\text { Uncultured Deltaproteobacteria; } \\
\text { Sva0853 }\end{array}$ & $100 \%$ & HQ675271.1 \\
\hline OTU_31137 & SAR202 & Unclassified Chloroflexi & & \\
\hline OTU_15929 & AB16 & Uncultured SAR406 & $96 \%$ & JF488613.1 \\
\hline OTU_23515 & Synechococcophycideae & Prochlorococcus & $100 \%$ & CP007753.1 \\
\hline OTU_23585 & Synechococcophycideae & Synechococcus sp. & $100 \%$ & JF306716.1 \\
\hline
\end{tabular}

in the composition of the microbial community on sinking particles over diel timescales. Moreover, the bulk particle samples in this study were enriched in taxa known to be found in association with particles and the composition was similar to that recently reported for traps deployed at various depths at Station ALOHA in the NPSG [3]. By contrast, the sequence libraries of individually picked particles $(\sim 50-200 \mu \mathrm{m}$ in diameter) showed large variations between the samples indicating that the individual particles are inhabited by specialized bacterial taxa and offer distinct ecological niches. Notably, the individual particles collected over the size range and characteristics that could be easily distinguished and picked using a micropipette were not representative of the bulk particle samples (Fig. 4 and Supplementary Figure S2). This potentially underscores the importance of small particles for carbon flux [54].
The 16S rRNA gene libraries indicated that the particles contained both large and small size classes of cyanobacterial diazotrophs. This was further confirmed by amplification and sequencing of the nifH gene in a majority of the individual particles. Our results demonstrate that in addition to diazotrophs associated with larger cells such as the diatom-Richelia symbiosis [19] typically associated with sinking particles, unicellular cyanobacterial diazotrophs were also contributing to direct POM export. Unicellular cyanobacterial diazotrophs have previously been visualized in association with inert particles and in association with eukaryotic cells $[55,56]$. However, the cellular strategies of unicellular cyanobacterial diazotrophs and whether they contribute to $\mathrm{N}_{2}$ fixation rates in both the freeliving and particulate fractions has not yet been resolved. Why cyanobacterial diazotrophs of diverse size classes are found in association with sinking particles-a process that 

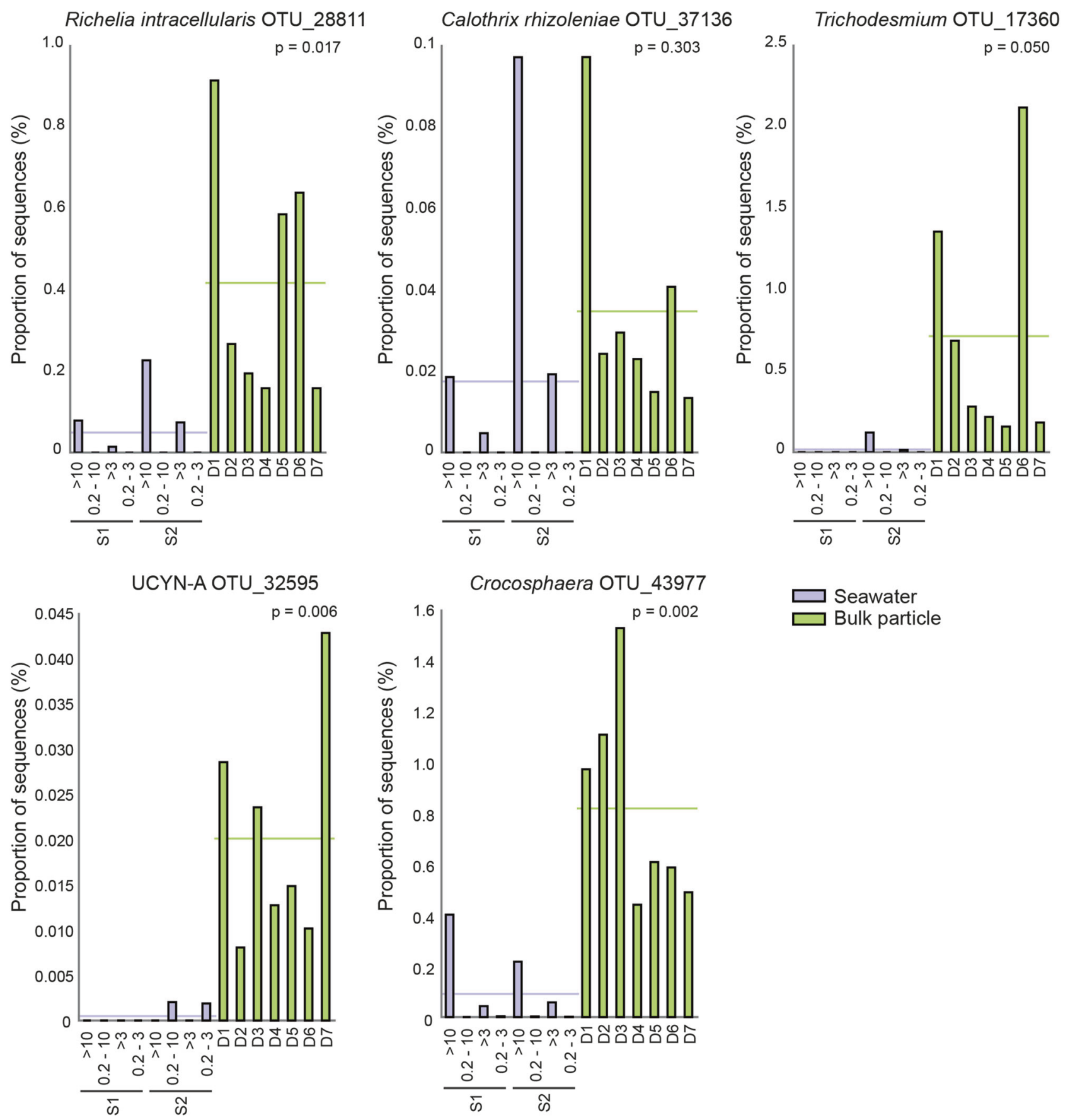

Fig. 6 Group comparison of the sequence library proportions of OTUs related to the 16S rRNA genes of known diazotrophs (>97\% identity) in seawater and bulk particle samples. The bar plots show the proportion of sequences for each sample. The seawater samples (S1 and
$\mathrm{S} 2 ;>10,0.2-10,>3$, and $0.2-3 \mu \mathrm{m})$ are shown in purple and the bulk particle samples from each net trap (D1-D7) are shown in green. The horizontal line in each graph shows the mean proportions of sequences for the respective sample groups and p-values are given for each graph ultimately removes them from the euphotic zone-and whether these diazotrophs are active on particles have yet to be determined.

The presence of unicellular cyanobacterial diazotrophs on particles has implications for the particular lifestyles of specific diazotroph species as some may be more prone to aggregation or grazing than others. At the time of sampling the unicellular diazotroph Crocosphaera was present at unusually high abundances which likely reflected their presence in collected bulk particle samples. Some strains of Crocosphaera are known to produce extracellular polysaccharides $[57,58]$ which can contribute to particle formation and thereby they may have a direct role in carbon export [59]. The widely distributed, uncultivated, symbiotic 


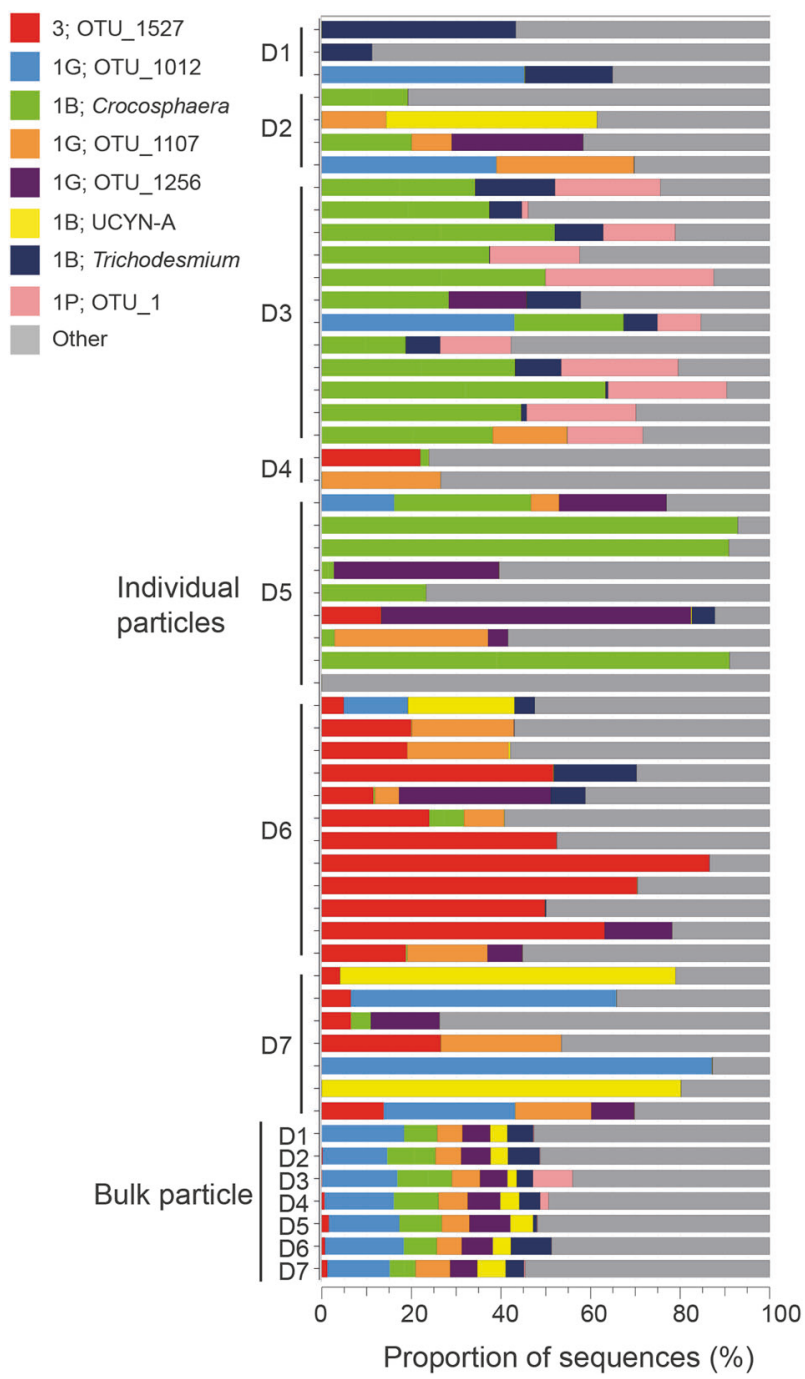

Fig. 7 Bar plot showing the proportion of nifH sequences of the nine most abundant OTUs (representing $\sim 60 \%$ of the total nifH sequences in the dataset) for each of the individual particles and bulk particle samples from each net trap (D1-D7). The legend indicates the nifH cluster affiliation and the OTU ID for each of the OTUs

$\mathrm{N}_{2}$-fixing cyanobacterium UCYN-A has distinct cooccurring sublineages, and in the NPSG, the two commonly occurring sublineages are UCYN-A1 and UCYN-A3 $[46,60]$. While the symbiotic partner of UCYN-A3 has not yet been identified or visualized, UCYN-A1 lives in association with a small haptophyte related to Braarudosphaera bigelowii and the size of the cell consortia is $1-3 \mu \mathrm{m}$ in diameter [60]. The enrichment of UCYN-A3 on particles suggests that these organisms aggregate on particles more efficiently or have adapted to a particle attached lifestyle. Thus, the strategies of the two closely related and cooccurring sublineages may be different.

A large proportion of the sequences in the nifH gene libraries in this study were from heterotrophic (non-cyanobacterial) diazotrophs. In the oligotrophic ocean, carbon substrates are sparse and are unlikely to support the demands of heterotrophic $\mathrm{N}_{2}$ fixation; consequently, their significance to $\mathrm{N}_{2}$ fixation has been debated. It has previously been hypothesized that nutrient-rich particles could support heterotrophic $\mathrm{N}_{2}$ fixation $[29,61]$. To our knowledge, this is the first study showing that diverse non-cyanobacterial diazotrophs are present on sinking particles which suggests that particles may be loci for heterotrophic $\mathrm{N}_{2}$ fixation.

Particles collected from net trap D6 contained a large proportion of Cluster III diazotrophs and may therefore have exhibited conditions that favored anaerobic or microaerophilic bacteria. A central anaerobic micro-zone which can support anaerobic processes has been demonstrated in mm-large particles and aggregates $[62,63]$ and anaerobic or microaerophilic bacteria were recently reported in association with the particle size fraction $(>3 \mu \mathrm{m})$ in the South China Sea [64] which suggests that bacteria with low $\mathrm{O}_{2}$ preferences could thrive on some particles. Cultivation studies of heterotrophic $\mathrm{N}_{2}$ fixation indicate that specific requirements of low $\mathrm{O}_{2}$ concentrations may be required for $\mathrm{N}_{2}$ fixation [65]. However, it was recently shown that the sulfate-reducing $\mathrm{N}_{2}$-fixing bacterium, Desulfovibrio magneticus, can grow in aerobic conditions [66]. Whether or not the particles that were picked in this study could provide the right conditions for Cluster III or other noncyanobacterial diazotrophs to grow or fix $\mathrm{N}_{2}$ is unknown. Yet at times, the high proportion of anaerobic diazotrophs present within individual particles such as those from net trap D6 suggested that they might have been significant.

Sequencing of gene amplicons is associated with several biases. For example, it has been suggested that the nifH primers used in this study may favor amplification of the gammaproteobacterial $\gamma 24774 \mathrm{~A} 11$ group [67], represented by OTU_1107 in this study, while the endosymbionts Richelia and Calothrix appear to be systematically underrepresented in sequence libraries [49]. Notably, in this study although represented in the $16 \mathrm{~S}$ rRNA gene libraries (up to $0.9 \%$, Fig. 6), the mean proportion of endosymbiont nifH groups (Het-1, Het-2 and Het-3) was low compared to other groups in the bulk particle samples $(5.0 \pm 1.8 \%)$. This highlights that the differences in relative abundances between taxa need to be interpreted cautiously. In addition, the sequencing of a DNA fragment does not provide information of whether the cell is alive or even intact, thus from sequencing data alone it cannot be determined whether the detected diazotrophs were active on particles or not. In future studies, measurements of absolute abundances and $\mathrm{N}_{2}$ fixation rates will be necessary to elucidate the significance of diazotrophs on particles but this may be technically challenging because of the heterogeneous nature of the particle pool [54].

To our knowledge, this is the first study which characterizes the bacterial composition and presence of diazotrophs on individual sinking particles collected in the ocean. The study shows that the heterogeneity in composition on 
particles is significant and indicates that diazotrophs are directly involved in POC export in the NPSG. The consistent presence of various size classes of diazotrophs warrant further investigations, including quantification of specific species and measurement of $\mathrm{N}_{2}$ fixation activity on particles. Further studies on microscale habitats will provide clues about the processes occurring within sinking particles and the important consequences for POC export in the oligotrophic ocean.

Acknowledgements We thank the C-MORE Team and the captain and crew of the R/V Ka'imikai-O-Kanaloa and HOE-Legacy 2B (KOK1507), as well as Chief Scientist Tara Clemente at the University of Hawaii for assistance with deploying and sampling particle net traps. We thank Benedetto Barone for construction of a previous version of Fig. 1. We would also like to acknowledge Stefan Green at the DNAS Facility at the University of Illinois at Chicago for the Illumina MiSeq sequencing. This work was supported by the Swedish Research Council VR 637-2013-7502 to HF. The study is a contribution of the Simons Collaboration on Ocean Processes and Ecology (SCOPE).

\section{Compliance with ethical standards}

Conflict of interest The authors declare that they have no conflict of interest.

Open Access This article is licensed under a Creative Commons Attribution 4.0 International License, which permits use, sharing, adaptation, distribution and reproduction in any medium or format, as long as you give appropriate credit to the original author(s) and the source, provide a link to the Creative Commons license, and indicate if changes were made. The images or other third party material in this article are included in the article's Creative Commons license, unless indicated otherwise in a credit line to the material. If material is not included in the article's Creative Commons license and your intended use is not permitted by statutory regulation or exceeds the permitted use, you will need to obtain permission directly from the copyright holder. To view a copy of this license, visit http://creativecommons. org/licenses/by/4.0/.

\section{References}

1. Simon M, Grossart HP, Schweitzer B, Ploug H. Microbial ecology of organic aggregates in aquatic ecosystems. Aquat Microb Ecol. 2002;28:175-211.

2. Falkowski PG, Barber RT, Smetacek V. Biogeochemical controls and feedbacks on ocean primary production. Science. 1998;281:200-6.

3. Fontanez KM, Eppley JM, Samo TJ, Karl DM, DeLong EF. Microbial community structure and function on sinking particles in the North Pacific Subtropical Gyre. Front Microbiol. 2015;6:469.

4. Guidi L, Chaffron S, Bittner L, Eveillard D, Larhlimi A, Roux S, et al. Plankton networks driving carbon export in the oligotrophic ocean. Nature. 2016;532:465-70.

5. Thiele S, Fuchs BM, Amann R, Iversen H. Colonization in the photic zone and subsequent changes during sinking determine bacterial community composition in marine snow. Appl Env Microbiol. 2015;81:1463-71.

6. Michaels AF, Silver MW. Primary production, sinking fluxes and the microbial food web. Deep Res. 1988;35:473-90.
7. Deng W, Cruz B, Neuer S. Effects of nutrient limitation on cell growth, TEP production and aggregate formation of marine Synechococcus. Aquat Microb Ecol. 2016;78:39-49.

8. Lomas MW, Moran SB. Evidence for aggregation and export of cyanobacteria and nano-eukaryotes from the Sargasso Sea euphotic zone. Biogeosciences. 2011;8:203-16.

9. Close HG, Shah SR, Ingalls AE, Diefendorf AF, Brodie EL, Hansman RL, et al. Export of submicron particulate organic matter to mesopelagic depth in an oligotrophic gyre. Proc Natl Acad Sci USA. 2013;110:12565-70.

10. Richardson T, Jackson G. Small phytoplankton and carbon export from the surface ocean. Science. 2007;315:838-40.

11. DeLong EF, Franks DG, Alldredge AL. Phylogenetic diversity of aggregate-attached vs. free-living marine bacterial assemblages. Limnol Oceanogr. 1993;38:924-34.

12. Kellogg CTE, Deming JW. Comparison of free-living, suspended particle, and aggregate-associated bacterial and archaeal communities in the Laptev Sea. Aquat Microb Ecol. 2009;57:1-18.

13. Rath J, Wu KY, Herndl GJ, DeLong EF. High phylogenetic diversity in a marine snow-associated bacterial assemblage. Aquat Microb Ecol. 1998;14:261-9.

14. LeCleir GR, Debruyn JM, Maas EW, Boyd PW, Wilhelm SW. Temporal changes in particle-associated microbial communities after interception by nonlethal sediment traps. FEMS Microbiol Ecol. 2014;87:153-63.

15. Pelve EA, Fontanez KM, DeLong EF. Bacterial succession on sinking particles in the ocean's interior. Front Microbiol. 2017;8:1-15.

16. Buesseler KO, Lamborg CH, Boyd PW, Lam PJ, Trull TW, Bidigare RR, et al. Revisiting carbon flux through the Ocean' $s$ Twilight Zone. Science. 2007;316:567-70.

17. Böttjer D, Dore JE, Karl DM, Letelier RM, Mahaffey C, Wilson ST, et al. Temporal variability of nitrogen fixation and particulate nitrogen export at Station ALOHA. Limnol Oceanogr. 2017;62:200-16.

18. Berthelot H, Moutin T, Helguen SL, Leblanc K, Hélias S, Grosso $\mathrm{O}$, et al. Dinitrogen fixation and dissolved organic nitrogen fueled primary production and particulate export during the VAHINE mesocosm experiment (New Caledonia lagoon). Biogeosciences. 2015;12:4099-12.

19. White AE, Foster RA, Benitez-Nelson CR, Masqué P, Verdeny E, Popp BN, et al. Nitrogen fixation in the Gulf of California and the Eastern Tropical North Pacific. Prog Oceanogr. 2013;109: $1-17$.

20. Capone DG, Zehr JP, Paerl HW, Bergman B, Carpenter EJ. Trichodesmium, a globally significant marine cyanobacterium. Science. 1997;276:1221-9.

21. Carpenter EJ, Montoya JP, Burns J, Mulholland MR, Subramaniam A, Capone DG. Extensive bloom of a $\mathrm{N}_{2}$-fixing diatom/ cyanobacterial association in the tropical Atlantic Ocean. Mar Ecol Prog Ser. 1999;185:273-83.

22. Alldredge AL, Gotschalk C. In situ settling behavior of marine snow. Limnol Ocean. 1988;33:339-51.

23. Bar-zeev E, Avishay I, Bidle KD, Berman-Frank I. Programmed cell death in the marine cyanobacterium Trichodesmium mediates carbon and nitrogen export. ISME J. 2013;7:2340-8.

24. Moisander PH, Beinart RA, Hewson I, White AE, Johnson KS, Carlson CA, et al. Unicellular cyanobacterial distributions broaden the oceanic $\mathrm{N}_{2}$ fixation domain. Science. 2010;327:1512-4.

25. Thompson AW, Zehr JP. Cellular interactions: lessons from the nitrogen-fixing cyanobacteria. J Phycol. 2013;49:1024-35.

26. Foster RA, Kuypers MMM, Vagner T, Paerl RW, Musat N, Zehr JP. Nitrogen fixation and transfer in open ocean diatom - cyanobacterial symbioses. ISME J. 2011;5:1484-93.

27. Farnelid H, Andersson AF, Bertilsson S, Al-Soud WA, Hansen LH, Sørensen S et al. Nitrogenase gene amplicons from global 
marine surface waters are dominated by genes of noncyanobacteria. PLoS One. 2011;6:e19223.

28. Moisander PH, Serros T, Paerl RW, Beinart RA, Zehr JP. Gammaproteobacterial diazotrophs and nifH gene expression in surface waters of the South Pacific Ocean. ISME J. 2014; 8:1962-73.

29. Bombar D, Paerl RW, Riemann L. Marine non-cyanobacterial diazotrophs: moving beyond molecular detection. Trends Microbiol. 2016;24:916-27.

30. Turk-Kubo KA, Karamchandani M, Capone DG, Zehr JP. The paradox of marine heterotrophic nitrogen fixation: abundances of heterotrophic diazotrophs do not account for nitrogen fixation rates in the Eastern Tropical South Pacific. Environ Microbiol. 2014;16:3095-114.

31. Ploug H. Small-scale oxygen fluxes and remineralization in sinking aggregates. Limnol Oceanogr. 2001;46:1624-31.

32. Ploug H, Bergkvist J. Oxygen diffusion limitation and ammonium production within sinking diatom aggregates under hypoxic and anoxic conditions. Mar Chem. 2015;176:142-9.

33. Peterson ML, Wakeham SG, Lee C, Askea MA, Miquel JC. Novel techniques for collection of sinking particles in the ocean and determining their settling rates. Limnol Oceanogr Methods. 2005;3:520-32.

34. Collins JR, Edwards BR, Thamatrakoln K, Ossolinski JE, DiTullio GR, Bidle KD, et al. The multiple fates of sinking particles in the North Atlantic Ocean. Glob Biogeochem Cycles. 2015;29:1471-92.

35. Green SJ, Venkatramanan R, Naqib A. Deconstructing the polymerase chain reaction: understanding and correcting bias associated with primer degeneracies and primer-template mismatches. PLoS One. 2015;10:e0128122.

36. Zehr JP, McReynolds LA. Use of degenerate oligonucleotides for amplification of the nifH gene from the marine cyanobacterium Trichodesmium thiebautii. Appl Env Microbiol. 1989;55:2522-6.

37. Moonsamy PV, Williams T, Bonella P, Holcomb CL, Höglund BN, Hillman G, et al. High throughput HLA genotyping using 454 sequencing and the Fluidigm Access Array ${ }^{\mathrm{TM}}$ system for simplified amplicon library preparation. Tissue Antigens. 2013;81:141-9.

38. Zhang J, Kobert K, Flouri T, Stamatakis A. PEAR: a fast and accurate Illumina Paired-End reAd mergeR. Bioinformatics. 2014;30:614-20.

39. Edgar RC, Haas BJ, Clemente JC, Quince C, Knight R. UCHIME improves sensitivity and speed of chimera detection. Bioinformatics. 2011;27:2194-200.

40. McDonald D, Price MN, Goodrich J, Nawrocki EP, DeSantis TZ, Probst A, et al. An improved Greengenes taxonomy with explicit ranks for ecological and evolutionary analyses of bacteria and archaea. ISME J. 2012;6:610-8.

41. Caporaso JG, Kuczynski J, Stombaugh J, Bittinger K, Bushman FD, Costello EK, et al. QIIME allows analysis of high- throughput community sequencing data. Nat Methods. 2010;7:335-6.

42. Robertson CE, Harris JK, Wagner BD, Granger D, Browne K, Tatem B, et al. Explicet: graphical user interface software for metadata-driven management, analysis and visualization of microbiome data. Bioinformatics. 2013;29:3100-1.

43. Parks DH, Beiko RG. Identifying biologically relevant differences between metagenomic communities. Bioinformatics. 2010;26:715-21.

44. Tamura K, Stecher G, Peterson D, Filipski A, Kumar S. MEGA6: molecular evolutionary genetics analysis version 6.0. Mol Biol Evol. 2013;30:2725-9.

45. Eren AM, Sul WJ, Murphy LG, Grim SL, Morrison HG, Sogin ML. Oligotyping: differentiating between closely related microbial taxa using 16S rRNA gene data. Methods Ecol Evol. 2013;4:1111-9.
46. Turk-Kubo KA, Farnelid HM, Shilova IN, Henke B, Zehr JP. Distinct ecological niches of marine symbiotic $\mathrm{N}_{2}$-fixing cyanobacterium Candidatus Atelocyanobacterium thalassa sublineages. J Phycol. 2017;53:451-61.

47. Zehr JP, Jenkins BD, Short SM, Steward GF. Nitrogenase gene diversity and microbial community structure: a cross-system comparison. Environ Microbiol. 2003;5:539-54.

48. Frank IE, Turk-Kubo KA, Zehr JP. Rapid annotation of nifH gene sequences using classification and regression trees facilitates environmental functional gene analysis. Environ Microbiol. 2016;8:905-16.

49. Turk-Kubo KA, Frank IE, Hogan ME, Desnues A, Bonnet S, Zehr JP. Diazotroph community succession during the VAHINE mesocosm experiment (New Caledonia lagoon). Biogeosciences. 2015;12:7435-52.

50. Wilson ST, Aylward FO, Ribalet F, Barone B, Casey JR, Connell $\mathrm{PE}$, et al. Coordinated regulation of growth, activity and transcription in natural populations of the unicellular nitrogen-fixing cyanobacterium Crocosphaera. Nat Microbiol. 2017;2:17118.

51. Villareal TA. Evaluation of nitrogen fixation in the diatom genus Rhizosolenia Ehr. in the absence of its cyanobacterial symbiont Richelia intracellularis Schmidt. J Plankt Res. 1987;9:965-71.

52. Hashimoto R, Watai H, Miyahara K, Sako Y. Spatial and temporal variability of unicellular diazotrophic cyanobacteria in the eastern Seto Inland Sea. Fishe. 2016;82:459.

53. Langlois R, Großkopf T, Mills M, Takeda S. Widespread distribution and expression of gamma A (UMB), an uncultured, diazotrophic, $\gamma$-proteobacterial nifH phylotype. PLoS One. 2015; 10:e128912.

54. Durkin CA, Estapa ML, Buesseler KO. Observations of carbon export by small sinking particles in the upper mesopelagic. Mar Chem. 2015;175:72-81.

55. Biegala IC, Raimbault P. High abundance of diazotrophic picocyanobacteria $(<3 \mathrm{um})$ in a Southwest Pacific coral lagoon. Aquat Microb Ecol. 2008;51:45-53.

56. Bonnet S, Biegala IC, Dutrieux P, Slemons LO, Capone DG. Nitrogen fixation in the western equatorial Pacific: rates, diazotrophic cyanobacterial size class distribution, and biogeochemical significance. Glob Biogeochem Cycles. 2009;23:GB3012.

57. Sohm JA, Edwards BR, Wilson BG, Webb EA. Constitutive extracellular polysaccharide (EPS) production by specific isolates of Crocosphaera watsonii. Front Microbiol. 2011;2:229.

58. Webb EA, Ehrenreich IM, Brown SL, Valois FW, Waterbury JB. Phenotypic and genotypic characterization of multiple strains of the diazotrophic cyanobacterium, Crocosphaera watsonii, isolated from the open ocean. Environ Microbiol. 2009;11:338-48.

59. Passow U. Transparent exopolymer particles (TEP) in aquatic environments. Prog Oceanogr. 2002;55:287-333.

60. Farnelid H, Turk-Kubo K, Muñoz-Marín M, Zehr J. New insights into the ecology of the globally significant uncultured nitrogenfixing symbiont UCYN-A. Aquat Microb Ecol. 2016;77:125-38.

61. Riemann L, Farnelid H, Steward G. Nitrogenase genes in noncyanobacterial plankton: prevalence, diversity and regulation in marine waters. Aquat Microb Ecol. 2010;61:235-47.

62. Klawonn I, Bonaglia S, Brüchert V, Ploug H. Aerobic and anaerobic nitrogen transformation processes in $\mathrm{N}_{2}$-fixing cyanobacterial aggregates. ISME J. 2015;9:1456-66.

63. Wilbanks EG, Salman-Carvalho V, Jaekel U, Humphrey PT, Eisen JA, Buckley DH, et al. The green berry consortia of the Sippewissett salt marsh: Millimeter-sized aggregates of diazotrophic unicellular cyanobacteria. Front Microbiol. 2017;8:1623.

64. Zhang Y, Xiao W, Jiao N. Linking biochemical properties of particles to particle-attached and free-living bacterial community structure along the particle density gradient from freshwater to open ocean. J Geophys Res G Biogeosciences. 2016;121: 2261-74. 
65. Farnelid H, Harder J, Bentzon-Tilia M, Riemann L. Isolation of heterotrophic diazotrophic bacteria from estuarine surface waters. Environ Microbiol. 2014;16:3072-82.

66. Lefèvre CT, Howse PA, Lefe CT, Schmidt ML, Sabaty M, Menguy $\mathrm{N}$, et al. Growth of magnetotactic sulfate-reducing bacteria in oxygen concentration gradient medium. Environ Microbiol Rep. 2016;8:1003-15.

67. Turk KA, Rees AP, Zehr JP, Pereira N, Swift P, Shelley R, et al. Nitrogen fixation and nitrogenase (nifH) expression in tropical waters of the eastern North Atlantic. ISME J. 2011;5:1201-12. 